\title{
Estimating the Relative Role of Various Subcategories of Food, Water, and Animal Contact Transmission of 28 Enteric Diseases in Canada
}

\author{
Ainslie J. Butler, Katarina D.M. Pintar, and M. Kate Thomas
}

\begin{abstract}
Objective: Enteric illness represents a significant burden of illness in Canada and internationally. Building on previous research, an expert elicitation was undertaken to explore the routes of transmission for 28 pathogens involved in enteric illness in Canada. This article considers the subcategories of foodborne, waterborne, and animal contact transmission.

Methods: As part of an expert elicitation, 31 experts were asked to provide estimates of source attribution for subcategories of foodborne $(n=15)$, waterborne $(n=10)$, and animal contact $(n=3)$ transmission. The results from an online survey were combined using triangular probability distributions, and median and $90 \%$ credible intervals were produced. The total proportion and estimated number of cases of enteric illness attributable to each type of food commodity, water source, and animal exposure route were calculated using results from the larger elicitation survey and from a recent Canadian foodborne burden of illness study (Thomas et al., 2013). Results: Thirty experts provided foodborne subcategory estimates for $15 / 28$ pathogens, waterborne subcategory estimates for $14 / 28$ pathogens and animal contact subcategory estimates for $5 / 28$. The elicitation identified raw produce, recreational water, and farm animal contact as important risk factors for enteric illness. These results also highlighted the complexity of transmission, with greater uncertainty for certain pathogens and routes of transmission. Conclusions: This study is the first of its kind to explore subcategories of foodborne, waterborne, and animal contact transmission across such a range of enteric pathogens. Despite inherent uncertainty, these estimates present an important quantitative synthesis of the roles of foodborne commodities, water sources, and pathways of animal contact in the transmission of enteric illness in Canada.
\end{abstract}

\section{Introduction}

$\mathbf{E}$ NTERIC INFECTIONS REPRESENT a significant burden of illness in Canada and globally. In Canada, there are an estimated 20.5 million cases of enteric illness annually $(95 \%$ confidence interval [CI]: 19.3-21.7 million) of which 4.0 million (95\% CI: 3.1-5.8 million) are estimated to be domestically acquired foodborne cases (Thomas et al., 2013). The pathways to human enteric illness are varied and complex and often poorly characterized.

Expert elicitation has previously been used as a source attribution tool, to explore the role of transmission in the most common enteric infections in Canada and around the world (Cressey and Lake, 2005; Hoffmann et al., 2006; Havelaar et al., 2008; Ravel et al., 2010; Vally et al., 2014; Butler et al., 2015). Some have focused particularly on subcategories of foodborne transmission (Hoffmann et al., 2006;
Havelaar et al., 2008; Davidson et al., 2011), but very limited data exist on waterborne and animal contact routes.

As part of the Public Health Agency of Canada's (PHAC) burden of enteric illness and source attribution efforts, an expert elicitation was undertaken to attribute transmission of 28 enteric pathogens (Butler et al., 2015). An objective of this study involved the elicitation of specific subcategory estimates for foodborne, waterborne, and animal contact transmission of these same pathogens, which is the focus of this article. This research will help inform future research and surveillance efforts in Canada.

\section{Materials and Methods}

A six-stage expert elicitation for the attribution of 28 enteric illnesses to five major routes of transmission and their respective subcategories was undertaken in January-April

Centre for Foodborne, Environmental, and Zoonotic Infectious Diseases, Public Health Agency of Canada, Ottawa, Canada.

(C) Ainslie J. Butler, et al. 2016; Published by Mary Ann Liebert, Inc. This Open Access article is distributed under the terms of the Creative Commons Attribution Noncommercial License (http://creativecommons.org/licenses/by-nc/4.0/) which permits any noncommercial use, distribution, and reproduction in any medium, provided the original author(s) and the source are credited. 
2014, methods described elsewhere (Butler et al., 2015). Briefly, a panel of 31 Canadian experts were each assigned 10 pathogens, based on self-assessed expertise collected in a presurvey.

Experts were asked to attribute 100 domestically acquired cases transmitted via food, water, or animal contact to their subcategories (Supplementary Material S1; Supplementary Data are available online at www.liebertpub.com/fpd). Experts could decline to produce subcategory estimates. Food subcategories in this study were based on Centers for Disease Control and Prevention guidelines for outbreak reporting (Painter et al., 2009), used in previous elicitations (Hoffmann et al., 2006; Havelaar et al., 2008; Davidson et al., 2011). Waterborne subcategories were differentiated by source water (recreational, bottled, private well, municipal groundwater, municipal surface water, and municipal ground water under the influence of surface water [GUDI]) and size of system (municipal system $>$ or $<10,000$ population serviced) (Murphy et al., 2015). Animal contact subcategories included exposure to wildlife, or domestic or farm animals. Experts were prompted to consider whether their foodborne subcategory estimates would change if considering attribution at the point of entry of contaminated foods into the domestic or commercial kitchen, and if so to quantify attribution of foodborne subcategories at the kitchen door.

Estimates were excluded where experts assessed confidence as 1/5 (low). Median and $90 \%$ credible intervals (CrI) for each subcategory were calculated from cumulative triangular probability distributions built using the Microsoft Excel add-in @Risk (Version 6.1.2; Palisade Corporation, Newfield, NY). Statistical methods are described elsewhere (Butler et al., 2015).

Cumulative estimates of transmission were combined with estimated distributions of annual cases for 28 pathogens obtained from recent Canadian burden of enteric illness estimates (Thomas et al., 2013). For enterotoxigenic Escherichia coli (ETEC), verotoxin-producing E. coli (VTEC) non-O157 and $E$. coli, other (non-VTEC, non-ETEC strains of $E$. coli), estimated domestic cases were determined by multiplying the domestic cases of VTEC O157 from Thomas et al. (2013) by the identified ratios relative to VTEC 0157 from Thomas et al. (2013), derived from Scallan et al. (2011) and Chui et al. (2011). The estimated distributions of domestic cases for each pathogen $\left(\mathrm{N}_{\text {pathogen }}\right)$ were multiplied by the cumulative distributions estimated via each of food, water, and animal contact transmission (e.g., $\mathrm{P}_{\text {pathogen }}[$ food]), derived from the first stage of the elicitation survey (Butler et al., 2015) using @ Risk. These estimates were then multiplied by the distributions of the proportion of cases transmitted by each subcategory (e.g., $\mathrm{P}_{\text {pathogen }}[$ beef]) to estimate how many cases were attributable to specific commodities (e.g., $\mathrm{N}_{\text {beef }}$ ), and their $90 \% \mathrm{CrI}$.

Ethics approval was obtained from Health Canada and PHAC's Research Ethics Board on January 13, 2014 (REB 2013-0033).

\section{Results}

Attribution estimates for specific subcategories of foodborne, waterborne, and animal contact transmission routes were provided by 30 of 31 participating experts. Responses were excluded where confidence was ranked as 1/5 (low), representing 7/148 (5\%) foodborne, 3/71 (4\%) waterborne, and 6/70 (9\%) animal contact transmission estimates. Data were also excluded for foodborne $(n=3)$ and waterborne $(n=1)$ transmission where major transmission route analysis indicated inappropriate clusters of responses (implying nonenteric transmission) (Butler et al., 2015).

Five or more experts provided foodborne subcategory estimates for $15 / 28$ pathogens; waterborne subcategory estimates for 5/28 pathogens; and animal contact estimates for $5 / 28$ pathogens. No subcategory estimates were provided for pathogens where less than 10 cases per 100 were attributed to that particular route (e.g., 8.3\% of adenovirus transmission attributed to food and no foodborne subcategory estimates were provided).

Kitchen door attribution estimates for foodborne transmission were provided for $13 / 28$ pathogens, with an average of two expert estimates per pathogen where provided. The shifts in attribution calculated from these estimates were negligible, but implied that cross-contamination, particularly from (raw) poultry in the kitchen, may play an important role in disease transmission, especially for Campylobacter spp. and nontyphoidal Salmonella spp.

Medians and $90 \% \mathrm{CrI}$ from the cumulative distributions for foodborne, waterborne, and animal contact transmission subcategories are presented in Tables 1, 2, and 3, respectively, for pathogens with $\geq 5$ experts responding. The elicited probability distributions should be interpreted with caution considering the uncertainty demonstrated in the CrI.

Using total pathogen estimates from the Canadian foodborne burden of illness estimates (Thomas et al., 2013), 90\% of cases of enteric illness with the 28 pathogens of interest were attributed to viruses, $8 \%$ to bacteria and $2 \%$ to parasites.

\section{Food}

For the foodborne estimates, raw produce was most frequently identified as the dominant source (3/14 pathogens) (Table 1); $21.8 \%$ (90\% CrI: 8.1-37.5) of all foodborne cases were attributed to raw produce, $18.3 \%(90 \% \mathrm{CrI}: 7.2-31.2)$ to seafood, and $<10 \%$ each to the remaining subcategories (Fig. 1). For bacterial infections, the most attributed food vehicle was "other" (15.4\%; 90\% CrI: 3.2-28.7), followed by poultry $(12.7 \%$; $90 \% \mathrm{CrI}$ : $2.9-24.8)$; raw produce was the most common food vehicle for parasitic $(25.2 \%$; $90 \% \mathrm{CrI}$ : 4.6-54.3) and viral (29.1\%; 90\% CrI: 0.0-48.9) infections (Fig. 1).

\section{Water}

For waterborne transmission, recreational water sources were the most commonly identified subcategory (3/5) (Table 2). Recreational water was attributed to the most cases overall within the waterborne transmission category $(23.8 \%$; 90\% CrI: 2.6-52.8), and specifically for parasites (24.2\%; 90\% CrI: 8.3-46.1) (Fig. 2). Private well water was most frequently implicated for bacterial $(29.4 \%$; 90\% CrI: $2.4-$ 64.9) and viral infections (23.5\%; 90\% CrI: 1.0-53.0) (Fig. 2).

\section{Animal}

Farm animal contact was the most common vehicle within animal contact transmission (5/5) (Table 3). The majority of 
Table 1. Most Likely Proportion and 90\% Credible Interval of Foodborne Transmission Attributable to Subcategories for 14 of 28 Pathogens at the Point of Consumption for Which More Than Five Experts Produced Estimates

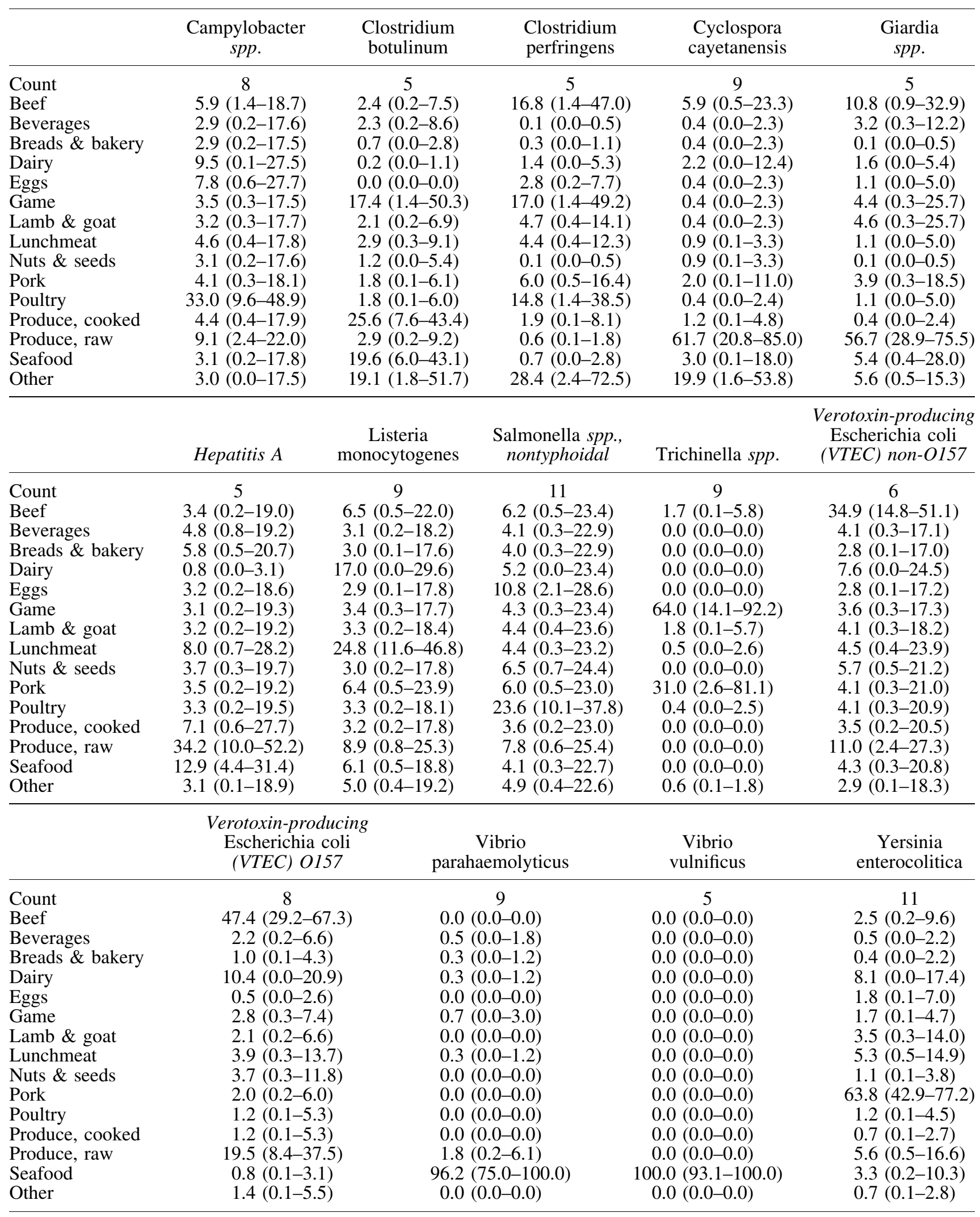


Table 2. Most Likely Proportion and 90\% Credible Interval Attributed to the 10 Subcategories Associated With Waterborne Transmission For 5 OF 28 Pathogens for Which More Than Five Experts Produced Estimates

\begin{tabular}{|c|c|c|c|c|c|}
\hline & $\begin{array}{l}\text { Campylobacter } \\
\text { spp. }\end{array}$ & $\begin{array}{c}\text { Cryptosporidium } \\
\text { spp. }\end{array}$ & Giardia $s p p$. & VTEC non-O157 & VTEC $O 157^{\mathrm{b}}$ \\
\hline Count & 6 & 7 & 7 & 5 & 5 \\
\hline Recreational water & $22.0(5.3-44.8)$ & $18.7(6.0-36.3)$ & $32.1(12.7-55.1)$ & $21.4(7.6-39.9)$ & $48.5(21.3-83.2)$ \\
\hline Private well & $27.2(13.1-44.5)$ & $15.0(2.4-37.7)$ & $19.7(8.0-34.2)$ & $29.0(14.4-47.2)$ & $25.6(5.9-47.1)$ \\
\hline $\begin{array}{l}\text { Ground water: large } \\
\text { municipal system }\end{array}$ & $5.2(0.4-25.7)$ & $7.4(0.6-30.8)$ & $1.7(0.1-5.7)$ & $6.1(0.4-26.0)$ & $0.9(0.1-3.3)$ \\
\hline $\begin{array}{l}\text { Ground water: small } \\
\text { municipal system }\end{array}$ & $5.5(0.5-22.6)$ & $8.5(0.7-31.2)$ & $2.9(0.2-8.1)$ & $7.2(1.4-26.4)$ & $4.9(1.3-11.0)$ \\
\hline $\begin{array}{l}\text { Surface water: large } \\
\text { municipal system }\end{array}$ & $4.5(0.3-22.6)$ & $8.4(0.7-30.5)$ & $13.0(1.1-37.5)$ & $4.7(0.3-29.6)$ & $1.6(0.1-5.9)$ \\
\hline $\begin{array}{l}\text { Surface water: small } \\
\text { municipal system }\end{array}$ & $7.7(0.8-23.7)$ & $12.0(2.1-32.2)$ & $9.0(0.9-23.5)$ & $7.6(1.5-29.4)$ & $7.5(2.1-16.0)$ \\
\hline $\begin{array}{l}\text { GUDI: large } \\
\text { municipal system }\end{array}$ & $4.0(0.3-22.4)$ & $8.0(0.7-30.4)$ & $6.9(0.6-28.0)$ & $6.4(0.9-30.1)$ & $2.1(0.2-6.9)$ \\
\hline $\begin{array}{l}\text { GUDI: small } \\
\text { municipal system }\end{array}$ & $12.5(1.1-12.5)$ & $10.1(1.0-10.1)$ & $6.7(0.6-6.7)$ & $7.4(1.4-7.4)$ & $7.8(2.1-7.8)$ \\
\hline Bottled water & $3.8(0.2-22.5)$ & $7.7(0.6-30.9)$ & $4.3(0.3-19.0)$ & $5.4(0.4-26.1)$ & $1.0(0.1-3.1)$ \\
\hline Other & $7.6(0.6-25.2)$ & $4.2(0.3-17.5)$ & $3.8(0.3-14.5)$ & $4.7(0.2-29.8)$ & $0.0(0.0-0.0)$ \\
\hline
\end{tabular}

${ }^{a}$ VTEC non-O157, verotoxin-producing Escherichia coli.

${ }^{b}$ VTEC O157, verotoxin-producing Escherichia coli.

GUDI, ground water under the influence of surface water.

animal contact cases were attributed to farm animals $(51.2 \%$; 90\% CrI: 5.5-100.0). Farm animal contact was identified as the main pathway for bacteria $(54.0 \%$; 90\% CrI: 8.5-100.0), parasites (44.3\%; 90\% CrI: 6.6-92.1), and viruses (51.4\%; 90\% CrI: 4.3-100.0) (Fig. 3).

\section{Discussion}

This study attributes the number of enteric cases related to 15 of 28 pathogens of public health importance in Canada to the subcategories of major enteric illness transmission routes (i.e., foodborne, waterborne, and animal contact). This study is one of the first to explore such an expansive list of enteric pathogens and has considered a wide range of viruses not considered in previous studies (Supplementary Material S2). Exploring the dominant sources of exposure to enteric pathogens, across and within transmission routes, is critical for public health initiatives targeted at reducing the burden of enteric illness in Canada. Identifying existing knowledge gaps related to enteric disease transmission dynamics in Canada is one outcome of this work.

\section{Food}

Raw produce was most frequently identified as the dominant source of foodborne transmission (7/24 pathogens) (Table 1). Of all foodborne cases, $21.8 \%$ (90\% CrI: 8.1-37.5) were attributed to raw produce, $18.3 \%$ (90\% CrI: $7.2-31.2)$ to seafood, and $<10 \%$ each to the remaining subcategories (Fig. 1). For bacterial infections, the most attributed food vehicle was "other" (15.4\%; 90\% CrI: 3.2-28.7), followed by poultry $(12.7 \%$; $90 \% \mathrm{CrI}: 2.9-24.8)$; raw produce was the most common food vehicle for parasitic $(25.2 \%$; $90 \% \mathrm{CrI}$ : 4.6-54.3) and viral (29.1\%; 90\% CrI: 0.0-48.9) infections (Fig. 1). These results are similar to estimates from previous elicitations and from analysis of outbreak data (Supplementary Material S2).

Infection with Trichinella spp. is attributed largely to game (64.0\% ; 90\% CrI: 14.1-92.2) and pork (31.0\% ; 90\% CrI: 2.6$81.1)$ in the current study. Routine testing of swine as part of the Canadian Food Inspection Agency (CFIA) Trichinella control program (CFIA, 2013) demonstrates that domestic commercial herds are Trichinella-free, despite a recent

Table 3. Most Likely Proportion and 90\% Credible Interval Attributable to the Three Subcategories Associated With Animal Contact Transmission for 5 of 28 Pathogens for Which More Than Five Experts Produced Estimates

\begin{tabular}{lccccc}
\hline & Campylobacter spp. & Giardia spp. & $\begin{array}{c}\text { Salmonella spp., } \\
\text { nontyphoidal }\end{array}$ & $\begin{array}{c}\text { VTEC O157 } \\
\text { Yersinia } \\
\text { enterocolitica }\end{array}$ \\
\hline Count & 8 & 7 & 9 & 7 & 7 \\
Domestic & $27.5(8.0-53.6)$ & $42.5(17.0-66.8)$ & $39.8(11.8-75.9)$ & $5.3(3.4-7.3)$ & $23.3(1.8-62.6)$ \\
Farm & $57.6(35.1-87.0)$ & $48.0(15.8-73.4)$ & $52.6(21.3-87.6)$ & $83.0(76.8-89.1)$ & $72.5(31.7-95.8)$ \\
Wildlife & $14.9(1.2-41.2)$ & $9.5(0.8-30.9)$ & $7.6(1.9-13.3)$ & $11.7(6.5-16.9)$ & $4.2(0.4-10.7)$ \\
\hline
\end{tabular}

${ }^{\mathrm{a}}$ VTEC O157, Verotoxin-producing Escherichia coli. 


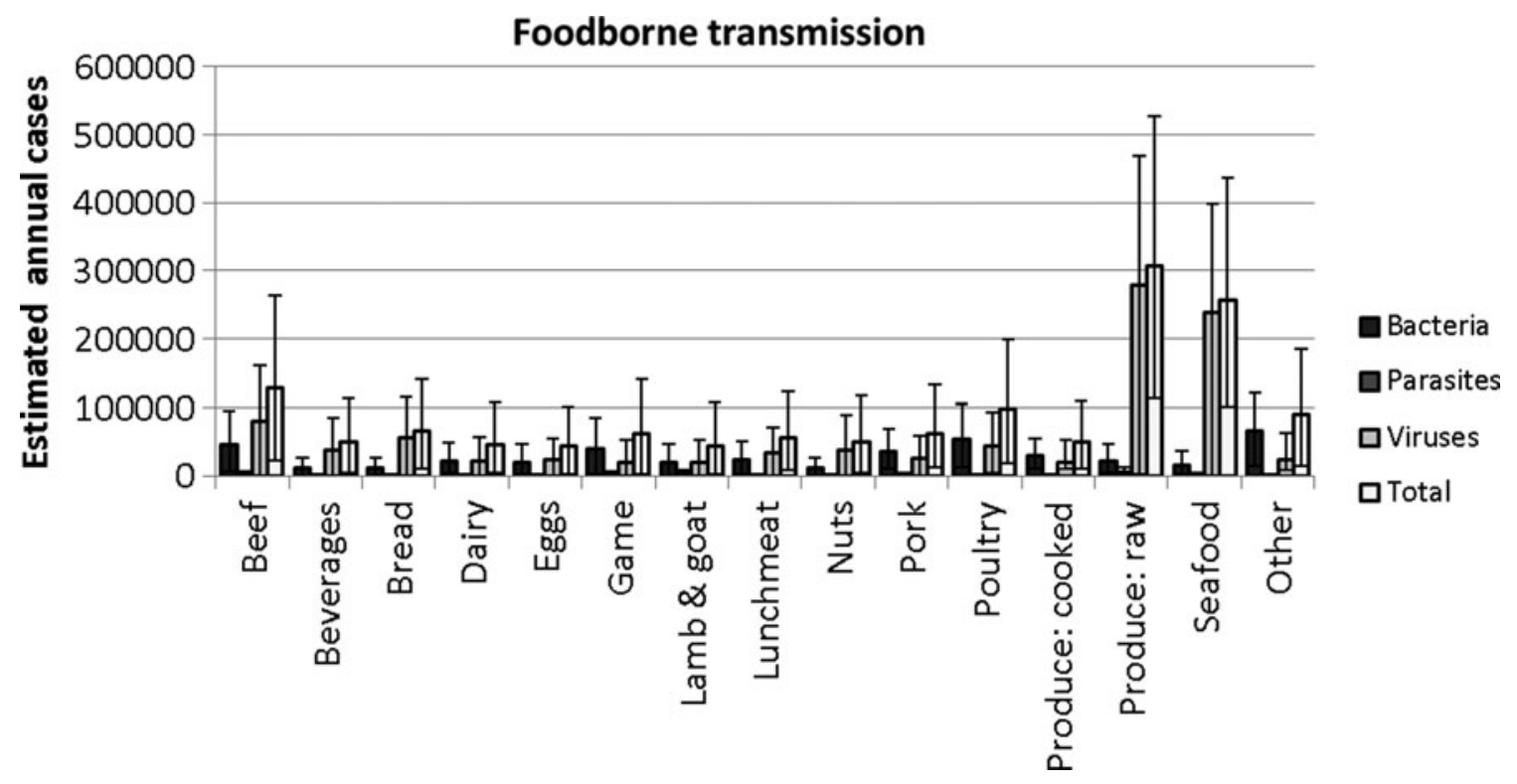

FIG. 1. Proportion of foodborne cases attributed to 15 subcategories, by pathogen types and as a total. Error bars represent $90 \%$ credible intervals.

(2013) case of human Trichinella spp. infection from a pig raised on a noncommercial farm (CFIA, 2013). This estimate highlights two limitations of this research design: (1) the inability to differentiate between domestic and imported foods: given the rarity of human trichinellosis, the role of imported meats could be significant; and (2) reliance of experts on historic trends over current exposures.

Beef was highlighted as the most important food commodity for VTEC O157 infections (47.4\%; 90\% CrI: 29.267.3 ), followed by produce: $19.5 \%$ raw and $1.2 \%$ cooked ( $20.7 \%$ total). This is similar to the previous Canadian elicitation, where beef was estimated to be responsible for 54.0-57.8\% of VTEC O157 infections, followed closely by produce (23.1-28.8\%) (Davidson et al., 2011). These results suggest consistency between the two Canadian studies, illustrating that for some infections, experts remain in consensus about the dominant sources.

Where estimates differ between this study and other Canadian studies (e.g., for Campylobacter spp. C. botulinum and Staphylococcus aureus), sources of disagreement are unclear. The differences in responses may reflect a lack of data from which experts can derive estimates, highlighting a knowledge gap for future research, given the role some of these pathogens play in the overall burden of foodborne illness. Alternately, they may reflect considerations related to food categories explored.

For Clostridium botulinum, current estimates indicate an important role of cooked (preserved) produce, which may

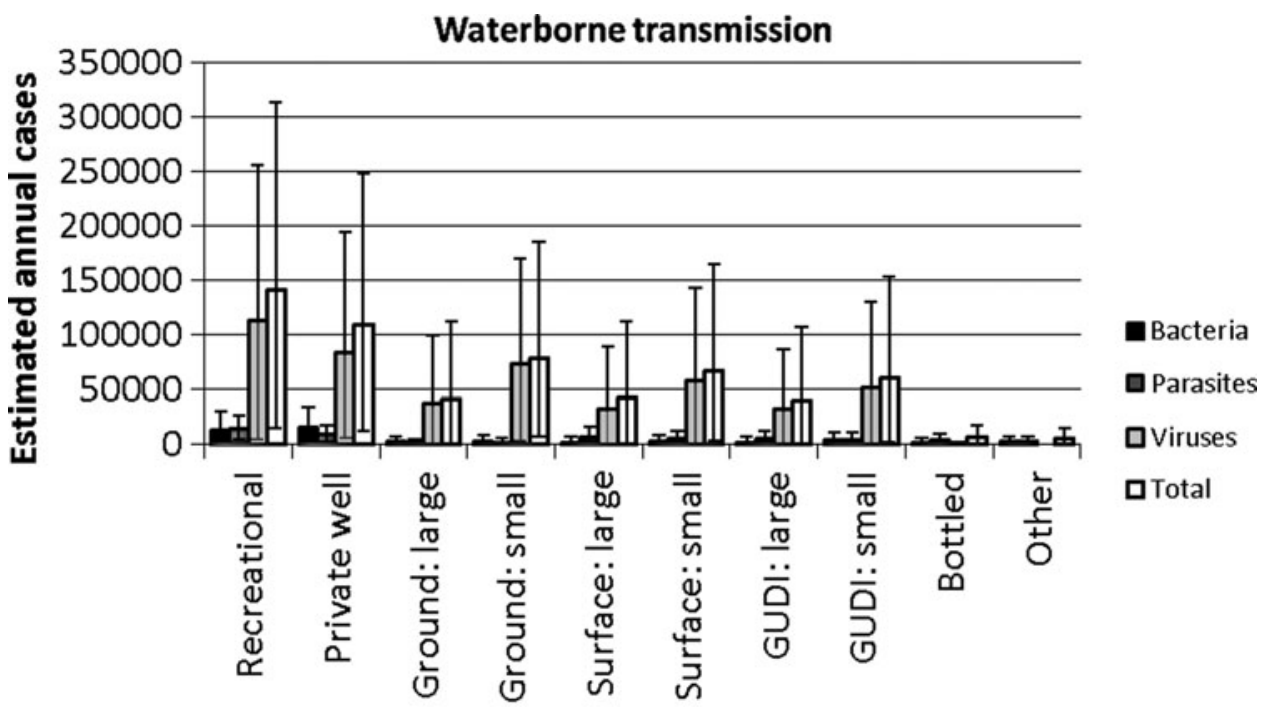

Subcategories of waterborne transmission

FIG. 2. Proportion of waterborne cases attributed to 10 subcategories, by pathogen types and as a total. Error bars represent $90 \%$ credible intervals. 


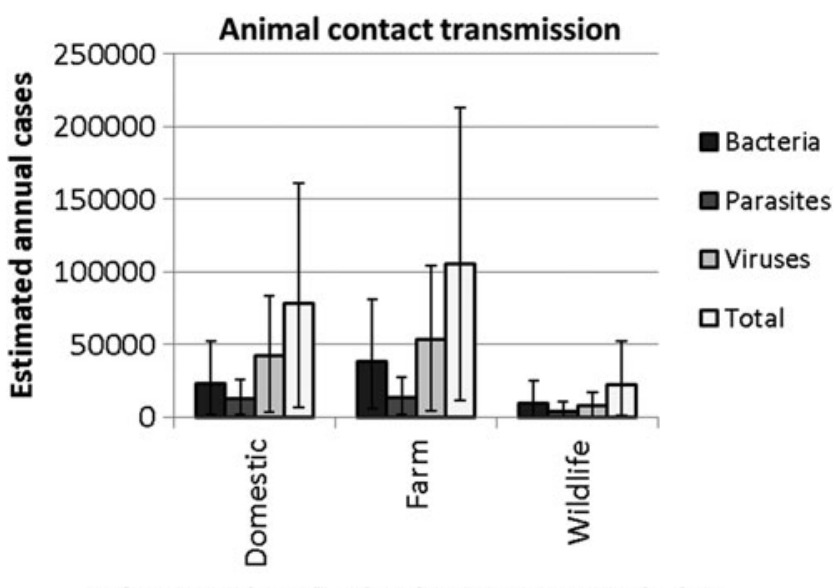

Subcategories of animal contact transmission

FIG. 3. Proportion of animal contact cases attributed to domestic, farm, and wildlife animal contact, by pathogen types and as a total. Error bars represent $90 \%$ credible intervals.

correspond to canned goods in the "other" category in retrospective outbreak studies (Greig and Ravel, 2009). However, in outbreak studies, seafood (Greig and Ravel, 2009) and game (Ravel et al., 2009) are identified as the dominant risk factors.

Cyclospora cayetanensis transmission is mostly attributed to raw produce $(61.7 \%$; 95\% CrI: $20.8-85.0)$, similar to the previous U.S. elicitation (Hoffmann et al., 2006) and outbreak studies from the United States (Batz et al., 2011) and internationally (Greig and Ravel, 2009). Epidemiological studies suggest that untreated drinking water and produce imported from endemic regions (particularly berries and salad greens) are significant risk factors, and the potential role of animals in transmission is unknown (Ortega and Sanchez, 2010).

Raw (unpasteurized) dairy consumption (especially milk) was identified in supplementary comments as an important transmission route for Campylobacter spp., VTEC O157, and VTEC non-O157. Raw milk was not specifically queried; however, dairy was implicated for Campylobacter spp. (9.5\%), Listeria monocytogenes (17.0\%), VTEC O157 (10.4\%), and VTEC non-O157 (7.6\%) (Table 1). The sale of raw milk is illegal in Canada, though cheeses made from raw milk are legal (Health Canada, 2014), and preliminary estimates indicate $3.1 \%$ of the Canadian population consumes raw milk and raw milk products.

\section{Water}

No previously published expert elicitations have explored the waterborne transmission route in such detail. Recreational water was attributed to the most cases overall within the waterborne transmission category $(23.8 \%$; $90 \%$ CrI: $2.6-$ $52.8)$, and specifically for parasites $(24.2 \%$; $90 \%$ CrI: $8.3-$ 46.1) (Fig. 2). Private well water was most frequently implicated for bacterial (29.4\%; 90\% CrI: 2.4-64.9) and viral infections (23.5\%; 90\% CrI: 1.0-53.0) (Fig. 2).

Recreational water exposure was identified as the main risk factor for $3 / 5$ pathogens for which estimates were provided (Table 2). Waterparks and pools have been recognized as important sources of Cryptosporidium spp. and Giardia spp. infections (Snel et al., 2009; Yoder et al., 2012a, b) and pool-associated outbreaks in the United States (Lam et al., 2014) and Canada (CCDR, 2004). Cryptosporidium spp., C. cayetanensis, and Giardia spp. are particularly resistant to chlorine, which is the most common type of disinfectant used in these settings (WHO, 2011). During the 1-day discussion, experts questioned the likelihood of sufficient persistence of other Vibrio spp. in Canadian water temperatures to facilitate waterborne infection (Tantillo et al., 2004). Domestic waterborne transmission of Vibrio spp. through enteric routes (i.e., not wound infection) is not believed to play a major role in transmission (3.8-11.0\% of Vibrio infection attributable to water) (Butler et al., 2015). Less than five experts provided estimates for any of the Vibrio spp. explored in this study., reflecting a lack of Canadian knowledge on this particular route of transmission.

Private wells were the primary source identified for $2 / 5$ pathogens (Table 2). Canadian studies have demonstrated the role of private well water as a risk for enteric illnesses (Uhlmann et al., 2009; Galanis et al., 2014). In this study, GUDI wells were implicated in viral infections more frequently than bacterial or parasitic infections (Fig. 2).

Attribution to municipal water systems was divided based on the size of population serviced by the municipal system: large municipal systems (>1000 population served, $13.3 \%$ of total waterborne cases) and small municipal systems $(<1000$ population served, $23.1 \%$ ). Size is used as a proxy of level of treatment, resources available to support treatment adoption, and operator training (Murphy et al., 2015).

Experts estimated that $<1 \%$ of total waterborne infection was attributable to bottled water. Bottled water has been involved in several outbreaks in the United States; however, there is no current evidence of waterborne infections associated with bottled water in Canada (Brunkard et al., 2011).

\section{Animal}

This is the first expert elicitation to consider sources within the animal contact transmission route. Previous elicitations in Australia and the Netherlands explored transmission via direct animal contact (Vally et al., 2014) and human and animal transmission (Havelaar et al., 2008); the current study elucidates source attribution more deeply. Animal contact transmission was defined as relating to illness transmitted by exposure to animals (i.e., personal contact [hand or mouth] with animal/pet feed, animal/pet fur/coats, saliva, or feces). Farm animal exposure was estimated as the most likely transmission route for all five pathogens for which estimates are provided (Table 3). The majority of animal contact cases were attributed to farm animals (51.2\%; 90\% CrI: 5.5-100.0), and specifically for bacteria (54.0\%; 90\% CrI: $8.5-100.0)$, parasites $(44.3 \%$; 90\% CrI: 6.692.1), and viruses (51.4\%; 90\% CrI: 4.3-100.0) (Fig. 3).

The likelihood of enteric pathogen transmission from household pets may be low compared to an encounter with farm animals or wildlife; however, the higher frequency of pet contact (David et al., 2014) would suggest this is an important exposure. Expert discussion highlighted the need to consider the relative extent to which frequent pet contact contributes to human enteric illness compared to low frequency exposure to farm animals and wildlife, and the relative risks, identified as a current knowledge gap in Canada. A limitation of these estimates is evident for animal contact transmission rotavirus, for which group discussion suggested 
zoonotic transmission was unlikely, yet animal contact transmission estimates have been produced (Table 3 ). This highlights the need to consider attribution estimates carefully in context of both the number of respondents and uncertainty as demonstrated by $\mathrm{CrI}$ width. A low response rate in this study is an indicator of a lack of knowledge for the specific pathogen and transmission route.

\section{Study limitations}

The limitations of this study are described in more detail in Butler et al. (2015). The study's greatest limitation is the low response rate, resulting in small panel sizes for some pathogen/ product combinations. Wide confidence intervals for estimates of certain pathogens and transmission routes reflect uncertainty that arises from lack of knowledge and data, highlighting areas for future research. Recall bias related to large-scale or notable outbreaks that have occurred in Canada or globally could have skewed the expert estimates to reflect high impact, low likelihood events. This study lacks the ability to differentiate between risks from imported and domestic food exposures.

This study does not characterize variations in exposure between the local and national level. It can be conceptually difficult to balance the role of local or geographically specific exposure while producing nationally representative estimates, which contributes to the range of uncertainty presented for each estimate. This limits our ability to differentiate between the variability and uncertainty that influences the widths of the credible intervals presented herein.

\section{Conclusions}

Expert elicitation is a useful tool for answering difficult questions where data are unavailable or expensive to obtain. This study explored the source attribution of 15 of 28 enteric pathogens at a previously unexplored level of detail for subcategories of foodborne, waterborne, and animal contact transmission. These results highlight the importance of raw produce, recreational water, and farm animal contact in transmission of enteric diseases as well as the complexity of transmission. While gaps in our understanding of source attribution remain, highlighting areas for future research, this study helps to improve our understanding of the role of food commodities and other sources in the transmission of enteric illness in Canada.

\section{Acknowledgments}

The researchers would like to thank all of the participating experts for their participation and engagement with this elicitation project. This research has been conducted under a National Sciences and Engineering Research Council postdoctoral research fellowship held by Ainslie Butler, working with the Centre for Food-borne, Environmental, and Zoonotic Infectious Diseases and FoodNet Canada (formerly C-Enternet) with the Public Health Agency of Canada.

\section{Disclosure Statement}

No competing financial interests exist.

\section{References}

Batz MB, Hoffman S, Morris JGJ. Ranking the risks: The 10 pathogen-food combinations with the greatest burden on public health. 2011;68. Available at: http://epi.ufl.edu/wpcontent/uploads/2011/04/RankingTheRisksREPORT.pdf, accessed on December 30, 2015.

Brunkard JM, Ailes E, Roberts VA, Hill V, Hilborn ED, Craun GF, Rajasingham A, Kahler A, Garrison L, Hicks L, Carpenter J, Wade TJ, Beach MJ, Yoder JS. Surveillance for waterborne disease outbreaks associated with drinking water-United States, 2007-2008. MMWR 2011;60(ss12):38-68.

Butler AJ, Thomas MK, Pintar KDM. Expert elicitation as a means to attribute 28 enteric pathogens to foodborne, waterborne, animal contact and person-to-person transmission routes. Foodborne Pathog Dis 2015;12:335-344.

[CCDR] Canada Communicable Disease Report. An outbreak of Cryptosporidium parvum in a Surrey pool with detection in pool water sampling. CCDR 2004;30:61-66.

[CFIA] Canadian Food Inspection Agency. TrichinellosisFact Sheet. 2013. Available at: http://www.inspection.gc.ca/ animals/terrestrial-animals/diseases/reportable/trichinellosis/ fact-sheet/eng/1330023015817/1330023110684, accessed October 6, 2014.

Chui L, Lee M, Malejczyk K, Lim L, Fok D, Kwong P. Prevalence of Shiga toxin-producing Escherichia coli (STEC) as detected by enzyme-linked immunoassays and real-time PCR during the summer months in Northern Alberta, Canada. J Clin Microbiol 2011;49:4307-4310.

Cressey P, Lake R. Ranking Food Safety Risks: Development of NZFSA Policy 2004-2005. Client Report FW0563:23. 2005. Available at: http://www.foodsafety.govt.nz/elibrary/ industry/Ranking_Food_Safety_Risks-Science_Research.pdf, accessed on December 30, 2015.

David JM, Ravel A, Nesbitt A, Pintar K, Pollari F. Assessing multiple foodborne, waterborne and environmental exposures of healthy people to potential enteric pathogen sources: Effect of age, gender, season, and recall period. Epidemiol Infect 2014;142:28-39.

Davidson VJ, Ravel A, Nguyen TN, Fazil A, Ruzante JM. Food-specific attribution of selected gastrointestinal illnesses: Estimates from a Canadian expert elicitation survey. Foodborne Pathog Dis 2011;8:983-995.

Galanis E, Mak S, Otterstatter M, Taylor M, Zubel M, Takaro TK, Kuo M, Michel P. The association between campylobacteriosis, agriculture and drinking water: A case-case study in a region of British Columbia, Canada, 2005-2009. Epidemiol Infect 2014;142:2075-2084.

Greig JD, Ravel A. Analysis of foodborne outbreak data reported internationally for source attribution. Int J Food Microbiol 2009;130:77-87.

Havelaar AH, Galindo AV, Kurowicka D, Cooke RM. Attribution of foodborne pathogens using structured expert elicitation. Foodborne Pathog Dis 2008;5:649-659.

Health Canada. Food and Drug Regulations (C.R.C., c. 870). 2014. Available at: http://laws-lois.justice.gc.ca/eng/regulations/ C.R.C.\%2C_c._870/, accessed September 25, 2014.

Hoffmann SA, Fischbeck PS, Krupnick AJ, McWilliams M. Attributing Foodborne Illnesses to Their Food Sources: Using Large Expert Panels to Capture Variability in Expert Judgment. Discussion Paper 06-17-REV. 2006. Available at: http://www.rff.org/files/sharepoint/WorkImages/Download/ RFF-DP-06-17-REV.pdf, accessed on December 30, 2015.

Lam S, Sivaramalingam B, Gangodawilage H. Cryptosporidium outbreaks associated with swimming pools. Environ Health Rev 2014;57:3-8.

Murphy HM, Thomas MK, Schmidt PJ, Medeiros DT, McFadyen $\mathrm{S}$, Pintar KDM. Estimating the burden of acute gastrointestinal illness due to Giardia, Cryptosporidium, Campylobacter, E. coli 
O157 and norovirus associated with private wells and small water systems in Canada. Epidemiol Infect 2015. doi:10.1017/ S0950268815002071.

Ortega YR, Sanchez R. Update on Cyclospora cayetanensis, a food-borne and waterborne parasite. Clin Microbiol Rev 2010;23:218-234.

Painter JA, Ayers T, Woodruff R, Blanton E, Perez N, Hoekstra RM, Griffin PM, Braden C. Recipes for foodborne outbreaks: A scheme for categorizing and grouping implicated foods. Foodborne Pathog Dis 2009;6:1259-1264.

Ravel A, Davidson VJ, Ruzante JM, Fazil A. Foodborne proportion of gastrointestinal illness: Estimates from a Canadian expert elicitation survey. Foodborne Pathog Dis 2010;7:1463-1472.

Ravel A, Greig J, Tinga C, Todd E, Campbell G, Cassidy M, Marshall B, Pollari F. Exploring historical Canadian foodborne outbreak data sets for human illness attribution. J Food Prot 2009;72:1963-1976.

Scallan E, Hoekstra R, Angulo F, Tauxe R, Widdowson M, Roy S, Jones J, Griffin P. Foodborne Illness acquired in the United States-Major pathogens. Emerg Infect Dis 2011;17:7-15.

Snel SJ, Baker MG, Kamalesh V, French N, Learmonth J. A tale of two parasites: The comparative epidemiology of cryptosporidiosis and giardiasis. Epidemiol Infect 2009;137:1641-1650.

Tantillo GM, Fontanarosa M, Di Pinto A, Musti M. Updated perspectives on emerging vibrios associated with human infections. Lett Appl Microbiol 2004;39:117-126.

Thomas MK, Murray R, Flockhart L, Pintar K, Pollari F, Fazil A, Nesbitt A, Marshall B. Estimates of the burden of foodborne illness in Canada for 30 specified pathogens and unspecified agents, circa 2006. Foodborne Pathog Dis 2013;10: 639-648.
Uhlmann S, Galanis E, Takaro T, Mak S, Gustafson L, Embree $\mathrm{G}$, Bellack N, Corbett K, Isaac-Renton J. Where's the pump? Associating sporadic enteric disease with drinking water using a geographic information system, in British Columbia, Canada, 1996-2005. J Water Health 2009;7:692-698.

Vally H, Glass K, Ford L, Hall G, Kirk MD, Shadbolt C, Veitch M, Fullerton KE, Mustro J, Becker N. Proportion of illness acquired by foodborne transmission for nine enteric pathogens in Australia: An expert elicitation. Foodborne Pathog Dis 2014;11:727-733.

[WHO] World Health Organization. Guidelines for drinkingwater quality. 2011. Available at: http://www.who.int/water sanitation_health/publications/2011/dwq_guidelines/en/, accessed on December 30, 2015.

Yoder JS, Gargano JW, Wallace RM, Beach MJ. Giardiasis surveillance-United States, 2009-2010. MMWR 2012a;7: 13-23.

Yoder JS, Wallace RM, Collier SA, Beach MJ, Hlavsa MC. Cryptosporidiosis surveillance-United States, 2009-2010. MMWR 2012b;61:1-12.

Address correspondence to: Katarina D.M. Pintar, MSc, PhD Centre for Foodborne, Environmental, and Zoonotic Infectious Diseases Public Health Agency of Canada 130 Colonnade $R d$. Ottawa, ON K1A OK9, Canada

E-mail: katarina.pintar@phac-aspc.gc.ca 